ARTICLE

https://doi.org/10.1038/s41467-019-11528-8

\title{
Transition metal-free phosphonocarboxylation of alkenes with carbon dioxide via visible-light photoredox catalysis
}

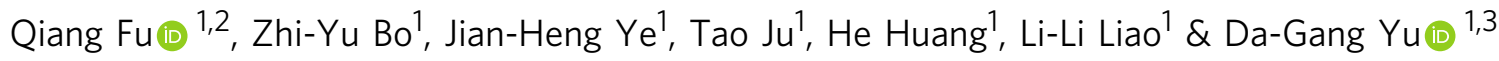

Catalytic difunctionalization of alkenes has been an ideal strategy to generate structurally complex molecules with diverse substitution patterns. Although both phosphonyl and carboxyl groups are valuable functional groups, the simultaneous incorporation of them via catalytic difunctionalization of alkenes, ideally from abundant, inexpensive and easy-tohandle raw materials, has not been realized. Herein, we report the phosphonocarboxylation of alkenes with $\mathrm{CO}_{2}$ via visible-light photoredox catalysis. This strategy is sustainable, general and practical, providing facile access to important $\beta$-phosphono carboxylic acids, including structurally complex unnatural $\alpha$-amino acids. Diverse alkenes, including enamides, styrenes, enolsilanes and acrylates, undergo such reactions efficiently under mild reaction conditions. Moreover, this method represents a rare example of redox-neutral difunctionalization of alkenes with $\mathrm{H}-\mathrm{P}(\mathrm{O})$ compounds, including diaryl- and dialkyl- phosphine oxides and phosphites. Importantly, these transition-metal-free reactions also feature low catalyst loading, high regio- and chemo-selectivities, good functional group tolerance, easy scalability and potential for product derivatization.

\footnotetext{
${ }^{1}$ Key Laboratory of Green Chemistry \& Technology of Ministry of Education, College of Chemistry, Sichuan University, 610064 Chengdu, P. R. China. ${ }^{2}$ Schoo of Pharmacy, Southwest Medical University, 646000 Luzhou, P. R. China. ${ }^{3}$ State Key Laboratory of Elemento-Organic Chemistry, Nankai University, 300071 Tianjin, P. R. China. Correspondence and requests for materials should be addressed to D.-G.Y. (email: dgyu@scu.edu.cn)
} 
D ifunctionalization of alkenes has developed into a powerful tool in organic synthesis for generation of highly functionalized skeletons due to the easy availability of alkenes with different functional groups and diverse substitution modes $^{1-4}$. Catalytic difunctionalization of alkenes with $\mathrm{H}-\mathrm{P}(\mathrm{O})$ compounds is an important and ideal method to generate valuable organophosphine derivatives ${ }^{5-11}$, which are of great importance in agrochemicals ${ }^{12}$, functional materials ${ }^{13,14}$, synthetic ${ }^{15}$, and medicinal ${ }^{16,17}$ chemistry. Huge progress has been achieved in oxidative transformations (Fig. 1a) ${ }^{18-21}$, in which the electronrich alkyl radicals, in situ generated through addition of phosphonyl radicals to alkenes, are oxidized to alkyl cations and then trapped by the nucleophilic components. However, the redoxneutral difunctionalization of alkenes with $\mathrm{H}-\mathrm{P}(\mathrm{O})$ compounds remains very rare $^{22}$.

Phosphorus-containing carboxylic acids are highly valuable compounds and widely exist in natural products ${ }^{23}$, materials ${ }^{24}$, and pharmaceuticals, which exhibit a diverse range of biological activities, acting as inhibitors of urease, glutamate carboxypeptidase II, neuropeptidase $N$-acetylated $\alpha$-linked acidic dipeptidase (NAALADase), and so on ${ }^{25-28}$. Notably, the $\beta$ phosphono $\alpha$-amino acids are important motifs in peptidic drugs, supramolecular catalysis (artificial metalloenzymes), and organic synthesis ${ }^{29-31}$. However, synthetic methods for such important compounds are extremely limited to de novo synthesis, which suffers from poor diversity, multiple steps, limited substrate scope, and/or harsh reaction conditions. We envisioned that the simultaneous incorporation of both phosphonyl and carboxyl groups via selective difunctionalization of enamides and other alkenes would serve as an ideal route to deliver important $\beta$ phosphono carboxylic acids, including $\beta$-phosphono $\alpha$-amino acids. Different from the above mentioned oxidative functionalization of the generated alkyl radicals ${ }^{18-21}$, we hypothesized that reduction of such key alkyl radicals to anions, which might undergo nucleophilic attack to $\mathrm{CO}_{2}$, could realize redox-neutral difunctionalization of alkenes with $\mathrm{H}-\mathrm{P}(\mathrm{O})$ compounds. To the best of our knowledge, this strategy has never been realized to generate such valuable targets.

Carbon dioxide $\left(\mathrm{CO}_{2}\right)$ has been regarded as a ubiquitous, green and recyclable one carbon $(\mathrm{C} 1)$ building block in organic synth$\mathrm{esis}^{32-38}$. Although the thermodynamic stability and kinetic inertness of $\mathrm{CO}_{2}$ introduces daunting challenges, a wide range of transformation using this gaseous reagent have been developed to construct important carboxylic acids, which are found in myriad natural products, agrochemicals, and pharmaceuticals ${ }^{39}$. Notably, catalytic carboxylation of unsaturated compounds with $\mathrm{CO}_{2}$ has attracted much attention of chemists ${ }^{38,40-49}$. Compared with widely investigated hydrocarboxylation of alkenes, however, catalytic difunctionalization of alkenes with $\mathrm{CO}_{2}$, which is obviously more attractive and cost-effective to obtain structurally complex molecules with diverse substitution patterns, is more challenging and much less investigated ${ }^{38}$. Although chemists have been mimicking Nature's ability for long time to harness light in organic transformations ${ }^{50-54}$ and transform $\mathrm{CO}_{2}$ to value-added products ${ }^{55,56}$, the visible-light-mediated difunctionalization of alkenes with $\mathrm{CO}_{2}$ is still scarce and yet underdeveloped with limited examples reported by Martin, $\mathrm{Wu}$ and our group, independently (Fig. 1b) ) $^{57-59}$. Moreover, photocatalytic difucnctionlization of the electron-rich alkenes, such as enamine and enol derivatives, with $\mathrm{CO}_{2}$ has not been reported yet, thus calling for a strategy to generate structurally more diverse $a$-amino acids $s^{60-62}$ and $\alpha$-hydroxy acids ${ }^{63}$.

Herein, we report the catalytic phosphonocarboxylation of diverse alkenes, including enamides, styrenes, enolsilanes, and acrylates, with $\mathrm{CO}_{2}$ (Fig. 1c). This strategy is sustainable, general, and practical, representing a rare example of redox-neutral difunctionalization of alkenes with $\mathrm{H}-\mathrm{P}(\mathrm{O})$ compounds to generate important $\beta$-phosphono carboxylic acids with high efficiency and selectivity under mild reaction conditions.

a

Transition metal-catalyzed oxidative phosphonylation of alkenes (Many reports)

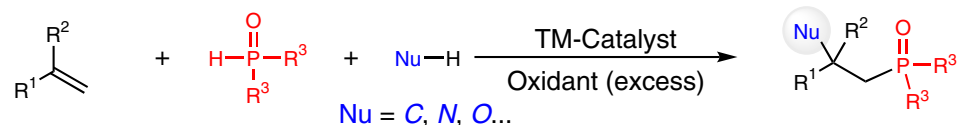

b $\mathrm{Nu}=C, N, O \ldots$

Visible-light-mediated difunctionalization of alkenes with $\mathrm{CO}_{2}$

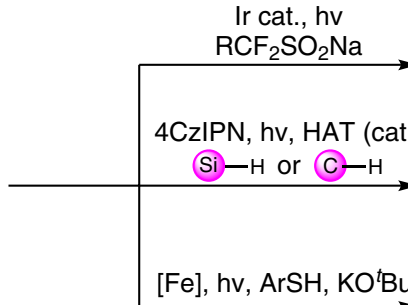<smiles>O=C(O)C(Br)C(P)C(F)F</smiles>

$\mathrm{HOOC} \mathrm{R}^{1}$<smiles>[R]C([Ge])C(Br)C(Br)(Br)C(=O)O</smiles>
Carbocarboxylation<smiles>O=C(O)CC([Ga])[Te]</smiles>

C Photoredox-catalyzed redox-neutral phosphonocarboxylation of alkenes (This work)

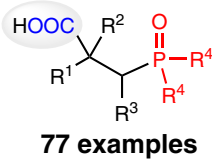

up to $93 \%$ yield
Wu' work: Silacarboxylation

Our previous work: Thiocarboxylation

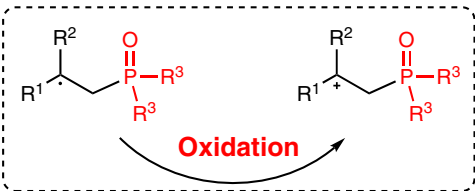

Martin' work: Carbocarboxylation

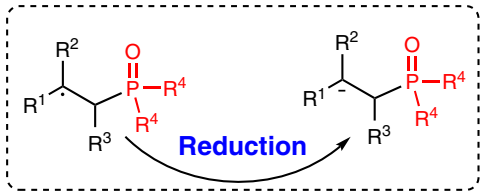

Enolsilanes

or Acrylates

Fig. 1 Catalytic difunctionalization of alkenes. a Oxidative difunctionalization of alkenes with $\mathrm{H}-\mathrm{P}(\mathrm{O})$ compounds. b Limited examples for visible-lightmediated difunctionalization of alkenes with $\mathrm{CO}_{2}$ reported by Martin, Wu and our group. c Redox-neutral difunctionalization of alkenes with $\mathrm{H}-\mathrm{P}(\mathrm{O})$ to generate important $\beta$-phosphono carboxylic acids, including structurally complex unnatural $\alpha$-amino acids 


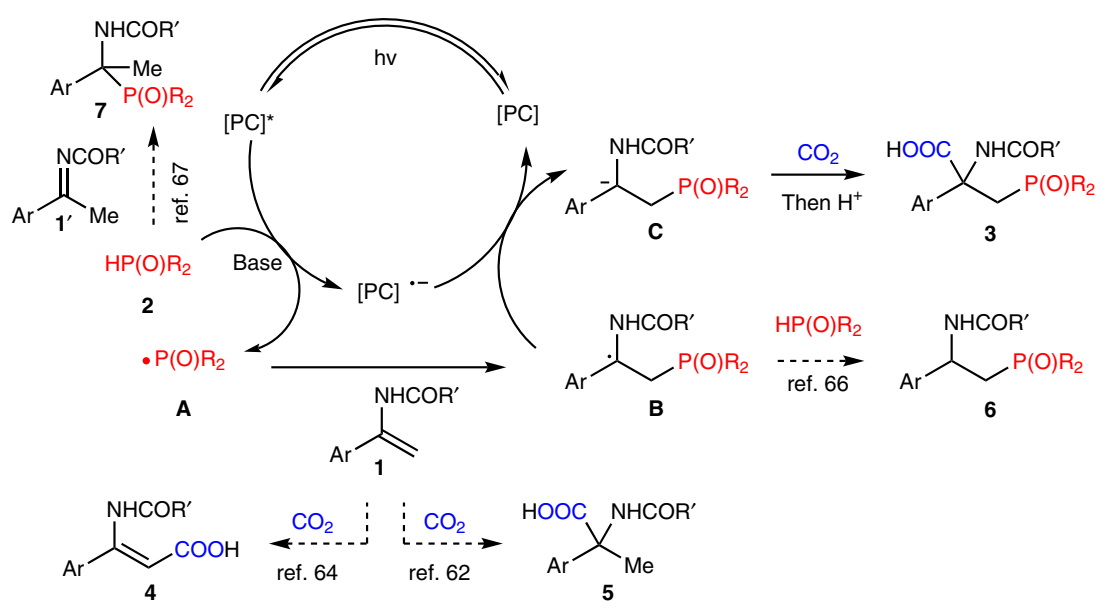

Fig. 2 Proposed mechanism for selective phosphonocarboxylation of enamides $\mathbf{1}$ with $\mathbf{2}$ to give $\mathbf{3}$. Compounds 4, 5, 6, and $\mathbf{7}$ are possible byproducts. [PC] $=$ photocatalyst

\section{Results}

Reaction design. At the beginning of this project, we challenged ourselves with realization of selective phosphonocarboxylation of enamides with $\mathrm{CO}_{2}$ via visible-light photoredox catalysis to generate valuable $\beta$-phosphono $\alpha$-amino acids. As proposed in Fig. 2, the phosphonyl radicals $\mathbf{A}$, generated via single-electron transfer (SET) between $\mathrm{H}-\mathrm{P}(\mathrm{O})$ compounds 2 and a photoexcited photocatalyst in the presence of a base, might undergo facile addition to the $\mathrm{C}=\mathrm{C}$ double bonds of enamides $\mathbf{1}$ to selectively generate the $\alpha$-amido radicals $\mathbf{B}$, which was stabilized by phenyl and amide groups. A subsequent SET between $\mathbf{B}$ and the reduced photocatalyst might give rise to the $\alpha$-amido carbanions $\mathbf{C}$, which then could react with $\mathrm{CO}_{2}$ to deliver the desired $\beta$-phosphono $\alpha$-amino acids 3 . However, the possible hydrocarboxylation $^{62}, \mathrm{C}-\mathrm{H}$ bond carboxylation ${ }^{64}$ of enamides as well as hydrophosphinylation (Pudovik reaction) ${ }^{65}$ via hydrogen atom transfer (HAT) ${ }^{66}$ between $\mathbf{B}$ and 2 could be competitive side reactions and generate 4,5 , and $\mathbf{6}$, respectively. The tautomerization between enamides $\mathbf{1}$ with imines $\mathbf{1}^{\prime}$ also should be considered, given that the latter species could be attacked by 2 to give a-amidophosphonate $7^{67}$.

Investigations of reaction conditions. We began our investigations using $N$-(1-phenylvinyl)benzamide $\mathbf{1 a}$ and diphenylphosphine oxide 2 a as model substrates with atmospheric $\mathrm{CO}_{2}$ under visible light irradiation at room temperature (Table 1). To our delight, we detected the formation of $\beta$-phosphono $\alpha$-amino acid 3aa using $\mathrm{Ru}(\mathrm{bpy})_{3} \mathrm{Cl}_{2}$ as the catalyst and $\mathrm{Cs}_{2} \mathrm{CO}_{3}$ as the base, albeit in trace amounts (Table 1, entry 1). When we tested other photocatalysts, we found that an Ir-based photocatalyst significantly improved the efficiency for generation of $\mathbf{3 a a}(70 \%$, Table 1, entry 2) and the organic photocatalyst 1,2,3,5-tetrakis (carbazol-9-yl)-4,6-dicyanobenzene (4CzIPN) provided the best result (75\%, Table 1, entry 3$)$. Importantly, in the absence of such photocatalysts, $4 \mathbf{a}(19 \%)^{64}$ and $7 \mathbf{a}(41 \%)^{67}$ were generated instead of 3aa (Table 1, entry 4). Further screening of various bases (Table 1, entries 5-7) showed that $\mathrm{K}_{2} \mathrm{CO}_{3}$ was the best choice (Table 1, entry 6), while the use of triethylamine as the base (Table 1, entry 7) would generate 5a $(29 \%)^{62}$ and $\mathbf{6 a}(24 \%)^{65,66}$ along with 3 aa $(32 \%)$. Intriguingly, the amount of photocatalyst could be even reduced to $0.1 \%$ without interfering the reaction (89\%, Table 1, entry 8), illustrating the high efficiency of the reaction. Control experiments revealed that $\mathrm{CO}_{2}$, light, photocatalyst, and base were all crucial for this transformation (Table 1, entries 9-12).
Substrate scope of enamides. With the acceptable reaction conditions in hand, a variety of $\beta$-phosphono $\alpha$-amino acids bearing a quaternary carbon center were obtained in moderate to excellent yields. As illustrated in Fig. 3, a diverse array of protecting groups for the enamines (3aa-3ca), including the readily removed Ac (3ba) and $\mathrm{Cbz}$ (3ca) carbamate, proved to be compatible with the light-driven phosphocarboxylation reaction. Notably, the enamides bearing electron-donating (methoxyl, 3ea) or electron-withdrawing groups (trifluoromethyl, 3ga) as well as heteroarenes, such as thiophene (3ha) and furan (3ia), all reacted well. We next turned our attention to the substituents on arenes. As also shown in Fig. 3, a broad range of aryl enamides bearing different functional groups, including methyl (3ja), methoxyl (3ka), phenyl (3la), halogens (3ma-3oa), and trifluoromethoxyl (3pa) at the para-position, afforded the desired products in moderate to excellent yields. The enamides with meta(3qa-3ta) and ortho-substituted arenes (3ua-3wa) also underwent such a transformation with high efficiency. The current protocol could also be applied to the substrates bearing di-substitution (3xa), internal enamides (3ya) and naphthalene (3za). Enamides containing pyridine (3aaa and 3aba) could also be tolerated in the reaction. Unfortunately, when alkyl enamide (1ac) was used as substrate in the reaction, we did not detected the desired carboxylative product 3aca while the hydrophosphinylation product 6ac was obtained.

Substrate scope of $\mathbf{H}-\mathbf{P}(\mathbf{O})$ compounds. Having demonstrated the good functional group compatibility in the enamide substrates, we next investigated the scope of the $\mathrm{H}-\mathrm{P}(\mathrm{O})$ compounds 2 . As illustrated in Fig. 4, a broad range of phosphorus-containing $\alpha$ amino acids were obtained. Both electron-donating (3ab-3ad) and mildly electron-withdrawing substituents (3ae-3af) on the aryl groups were well tolerated, leading to the desired products in good yields $(62-90 \%)$. It is important to note that this transformation is not restricted to diarylphosphine oxides, various phosphites (3ag3ak), which usually did not work well in the photochemical reactions, also could deliver the corresponding products smoothly, illustrating the synthetic utility and flexibility of this approach. Notably, dialkyl phosphine oxide, such as 3al, also took part in the reaction to provide the desired product in moderate yield (56\%), which demonstrates the generality of our transformation.

Substrate scope of styrenes. Considering the importance of $\beta$ phosphono carboxylic acids ${ }^{23}$, we wondered whether styrenes 8 could be utilized in this phosphonocarboxylation process. To our delight, this protocol was easily applicable to a range of electronically diverse styrenes (Fig. 5). Diverse functional groups, 


\section{Table 1 Screening the reaction conditions ${ }^{\mathrm{a}}$}

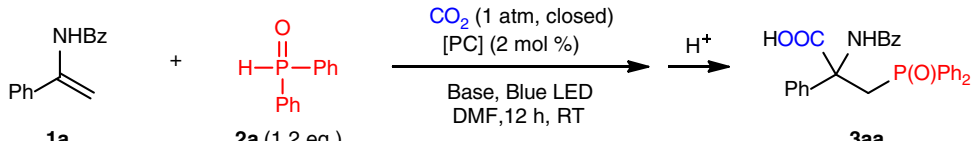

2a (1.2 eq.)
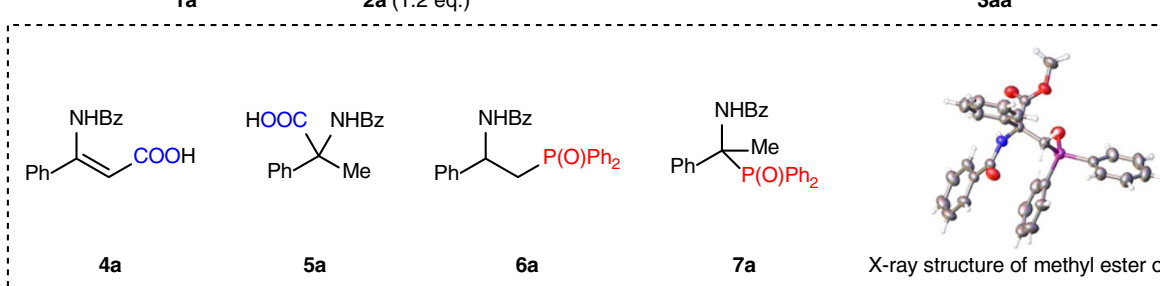

${ }_{\mathrm{Ph}}^{\mathrm{HOOC}} \mathrm{X}_{\mathrm{Me}}^{\mathrm{NHBz}}$<smiles>[R16]C(C[Po+][PH2+])c1ccccc1</smiles><smiles>[R16]C(N)([18OH])c1ccccc1</smiles>

$5 a$

6a

$7 a$ X-ray structure of methyl ester of $3 a a$

\begin{tabular}{llll}
\hline Entry & [PC] & Base & Yield (\%) \\
\hline 1 & $\mathrm{Ru}(\mathrm{bpy})_{3} \mathrm{Cl}_{2}$ & $\mathrm{Cs}_{2} \mathrm{CO}_{3}$ & $<5$ \\
2 & $\operatorname{Ir}\left[(\mathrm{ppy})_{2}(\mathrm{dtbpy})\right] \mathrm{PF}_{6}$ & $\mathrm{Cs}_{2} \mathrm{CO}_{3}$ & 70 \\
3 & $4 \mathrm{CzIPN}$ & $\mathrm{Cs}_{2} \mathrm{CO}_{3}$ & 75 \\
4 & - & $\mathrm{Cs}_{2} \mathrm{CO}_{3}$ & $\mathrm{~N} . \mathrm{D}$. \\
5 & $4 \mathrm{CzIPN}$ & $\mathrm{Na}_{2} \mathrm{CO}_{3}$ & 83 \\
6 & $4 \mathrm{CzIPN}$ & $\mathrm{K}_{2} \mathrm{CO}_{3}$ & 89 \\
7 & $4 \mathrm{CzIPN}$ & $\mathrm{Et}_{3} \mathrm{~N}$ & 32 \\
$8^{\mathrm{b}}$ & $4 \mathrm{CzIPN}$ & $\mathrm{K}_{2} \mathrm{CO}_{3}$ & 89 \\
$9^{\mathrm{b}, \mathrm{c}}$ & $4 \mathrm{CzIPN}$ & $\mathrm{K}_{2} \mathrm{CO}_{3}$ & $<5$ \\
10 & - & $\mathrm{K}_{2} \mathrm{CO}_{3}$ & $\mathrm{~N} . \mathrm{D}$. \\
$11^{\mathrm{b}, \mathrm{d}}$ & $4 \mathrm{CzIPN}$ & $\mathrm{K}_{2} \mathrm{CO}_{3}$ & N.D. \\
$12^{\mathrm{b}}$ & $4 \mathrm{CzIPN}$ & - & 21
\end{tabular}

LED light-emitting diode, DMF $N$, N-dimethylformamide, N.D. not detected

aReaction conditions: 1a $(0.2 \mathrm{mmol}), \mathbf{2 a}(1.2 \mathrm{eq}),.[\mathrm{PC}](2 \mathrm{~mol} \%)$, Base (1.5 eq.), DMF ( $2 \mathrm{~mL}), \mathrm{RT}$. The yields are of isolated products

b $0.1 \mathrm{~mol} \%$ of $[\mathrm{PC}]$

'Without $\mathrm{CO}_{2}$

dWithout light

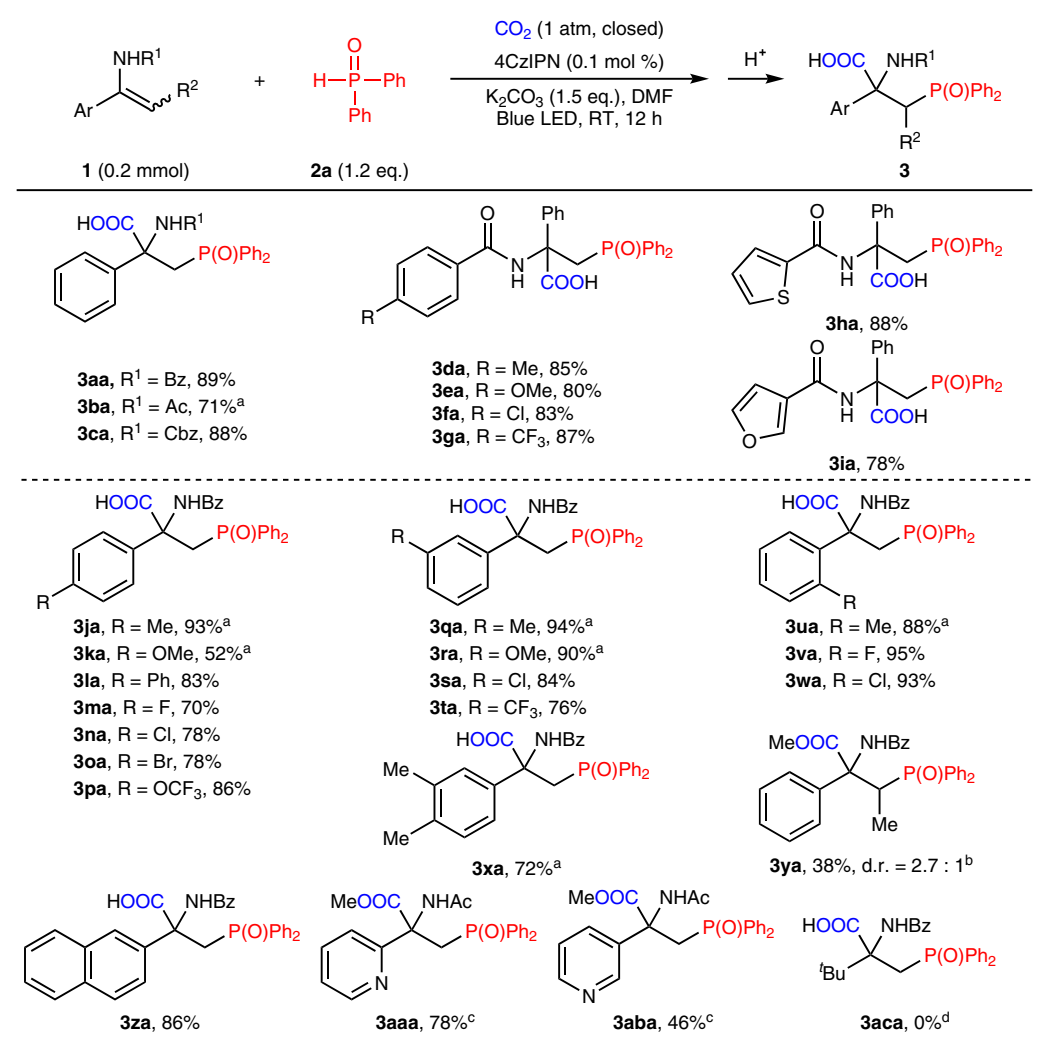

Fig. 3 Substrate scope of enamides. ${ }^{a} 4 \mathrm{CzIPN}\left(0.5 \mathrm{~mol} \%\right.$ ) was used ${ }^{\mathrm{b}}{ }^{2}=\mathrm{Me}$. ${ }^{\mathrm{C}}$ lsolated as methyl ester by treating the reaction mixture with $\mathrm{CH}_{3} \mathrm{l}$ at $65^{\circ} \mathrm{C}$ for $2 \mathrm{~h}$. ${ }^{\mathrm{d}}$ The hydrophosphinylation product $\mathbf{6 a c}$ was obtained 


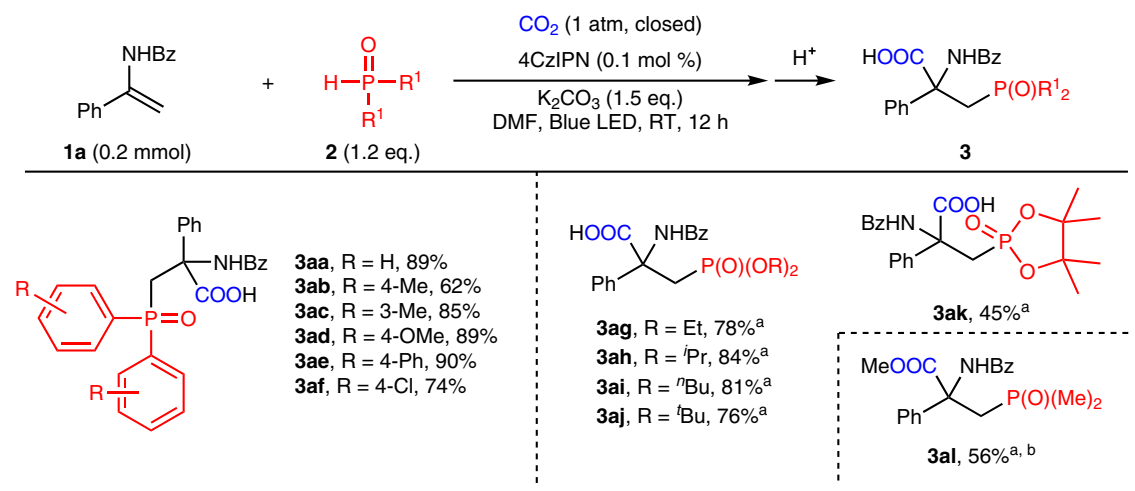

Fig. 4 Substrate scope of phosphine oxides and phosphites. ${ }^{\mathrm{a}} 4 \mathrm{CzIPN}(2 \mathrm{~mol} \%)$ and $\mathrm{Cs}_{2} \mathrm{CO}_{3}$ (1.5 eq.) were used. ${ }^{b}$ The yield for methyl ester of corresponding carboxylic acid is provided

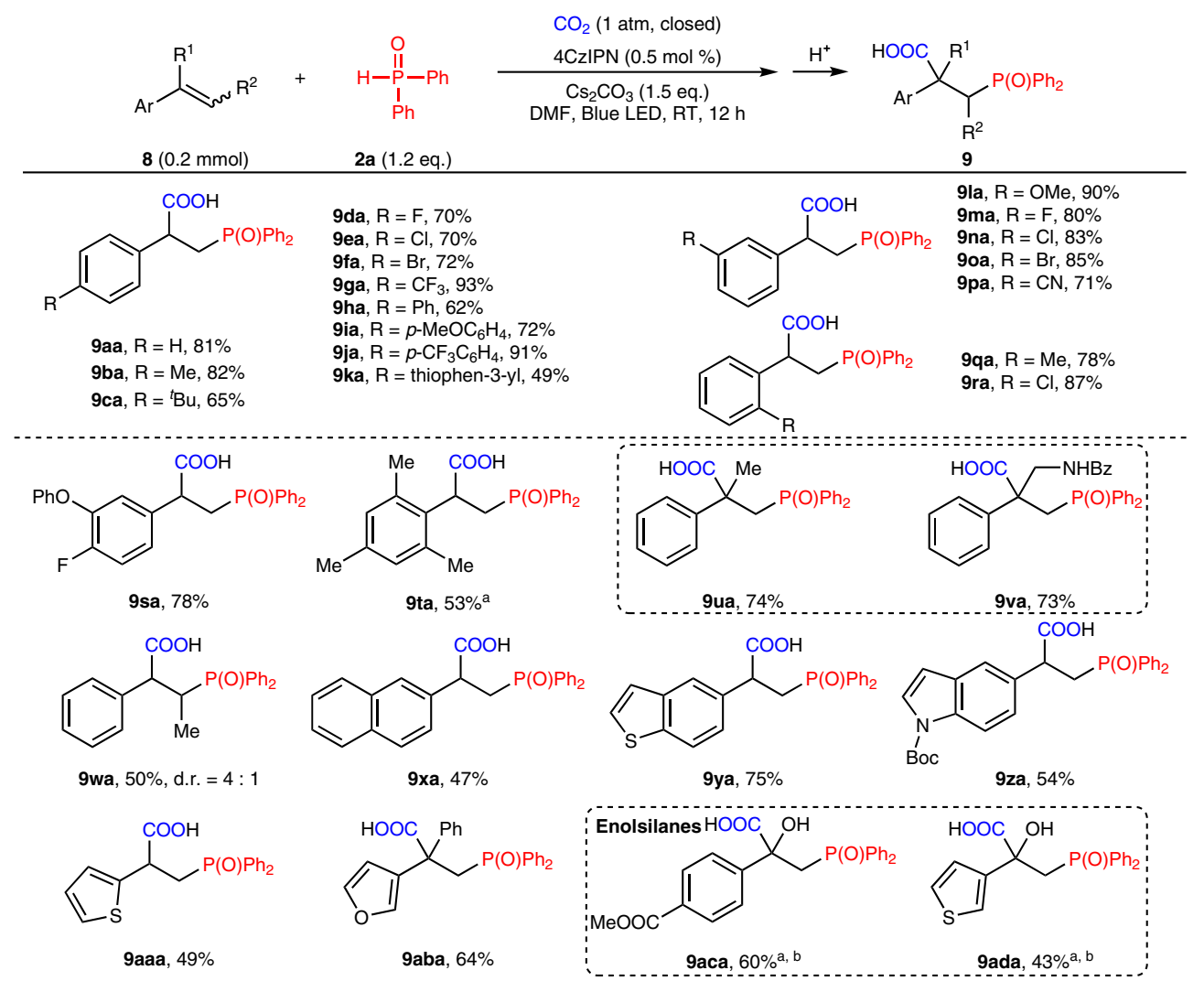

Fig. 5 Substrate scope of styrenes. a 4 CzIPN (2 mol\%) was used benolsilane was used as substrate, $\mathrm{R}^{1}=$ OTBS, TBS = tert-butyldimethylsilyl. Desilylation occurred upon acidifying the reaction mixture with aq. $\mathrm{HCl}(2 \mathrm{~N})$, providing $\alpha$-hydroxycarboxylic acid as the final product

including halogens (9da-9fa, 9ma-9oa, 9ra, 9ta), trifluoromethyl (9ga), nitrile (9pa), and heteroarenes (9ka, 9va) were tolerated well under the mild reaction conditions. The styrenes bearing disubstituted (9sa) and sterically hindered (2,4,6-trimethyl, 9ta) benzenes also delivered the desired products smoothly. Notably, the reaction also worked well for a-methyl or aminomethyl substituted styrenes (9ua, 9va), generating the products bearing quaternary carbon centers in good yields $(74 \%$ and $73 \%$, respectively). Other challenging alkenes, such as internal styrene (9wa) and heteroaryl-substituted styrenes (9xa-9aba), proved to be competent substrates in the reaction. Importantly, enolsilanes could also deliver the $\alpha$-hydroxy acids (9aca-9ada) in moderate yields. In addition, we did not detect the desired product when alkyl olefin, such as dec-1-ene, was subjected to the reaction.
Substrate scope of acrylates. To further demonstrate the generality of the phosphonocarboxylation reaction, we also explored electron-deficient acrylates (Fig. 6). Although the hydrophosphinylation of electron-deficient alkenes with 2 via nucleophilic addition has been well documented ${ }^{6}$, we were pleased to find that a broad range of acrylates $\mathbf{1 0}$ smoothly underwent our photocatalyzed phosphonocarboxylation transformation with diphenylphosphine oxide 2a. It is worth noting that when 3chloropropylacrylate was used as substrate, a multi-substituted six-membered ring lactone 11fa was obtained in good yield via intramolecular cyclization.

Synthetic applications. To demonstrate the potential application of the protocol, a gram-scale reaction was carried out to afford 


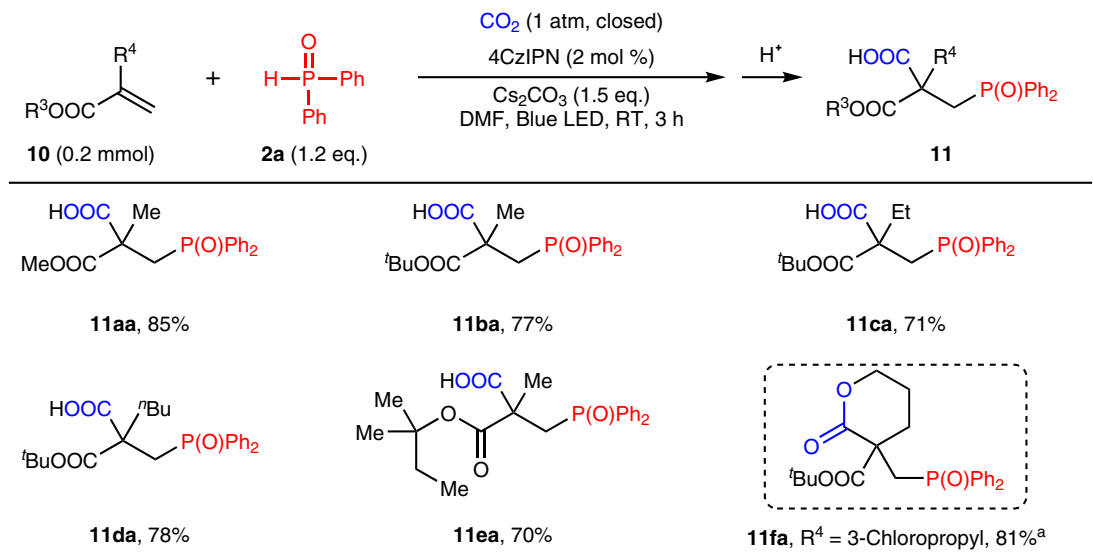

Fig. $\mathbf{6}$ Substrate scope of acrylates. ${ }^{a}$ When 3-chloropropylacrylate $\mathbf{1 0 f}$ was used as the substrate, a lactone $\mathbf{1 1 f a}$ was obtained via cascade intramolecular cyclization

a

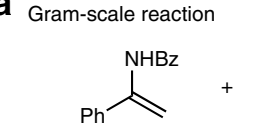

1a, $3.0 \mathrm{mmol}$

b

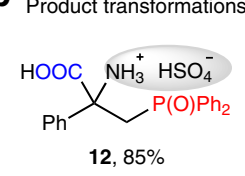

$12,85 \%$

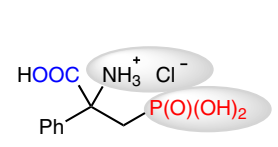

13, Quantitative (analogues of AP3)

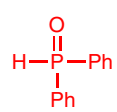

2a, $3.6 \mathrm{mmol}$

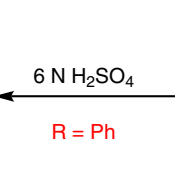

Hydrolysis

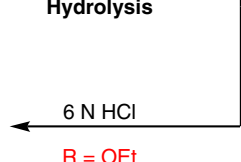

$\mathrm{R}=\mathrm{OEt}$

C

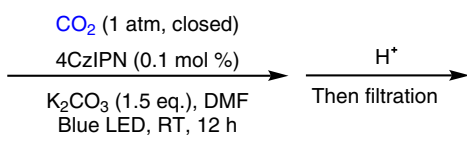

$\mathrm{K}_{2} \mathrm{CO}_{3}(1.5$ eq.), $\mathrm{DMF}$
Blue LED, RT, $12 \mathrm{~h}$

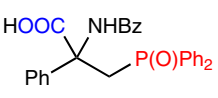

3aa, $1.04 \mathrm{~g}, 74 \%$
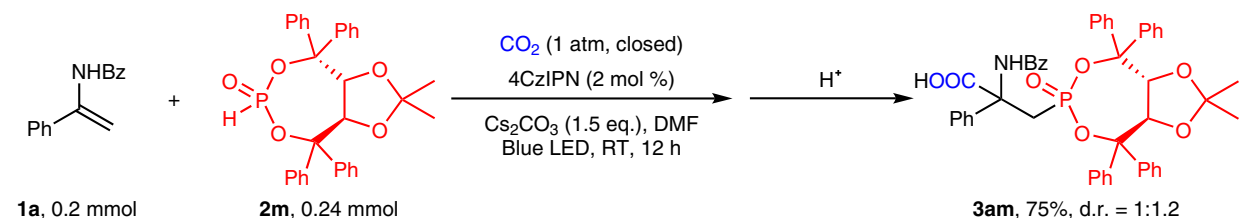

3am, $75 \%$, d.r. $=1: 1.2$

diastereoisomers could be separated

Fig. 7 Synthetic applications of the method. a Gram-scale synthesis free of isolation with chromatography. $\mathbf{b}$ Transformations of the product via hydrolysis and condensation. c Reaction with a chiral $\mathrm{H}-\mathrm{P}(\mathrm{O})$ compound. The diastereoisomers could be easily separated by column chromatography

3aa in $74 \%$ isolated yield without need of column chromatography (Fig. 7a). Moreover, the utility of the method was validated by facile derivatization of the products (Fig. 7b). For example, the benzoyl group could be removed easily to generate free $\beta$-phosphono $\alpha$-amino acid 12 in good yield (85\%). Hydrolysis of the benzamide and phosphite ester moieties in 3ag $(\mathrm{R}=$ OEt) quantitatively generated 13, an analogs of bioacitve AP3 ${ }^{69}$. Importantly, amino acids condensation between 3aa and methyl glycinate hydrochloride provided the phosphorus-containing dipeptide 14 (92\%) and intramolecular condensation of 3aa with the assistance of TFFA easily afforded cyclic oxazolinone $\mathbf{1 5 .}$ Furthermore, since reactions of chiral phosphorus-centered radicals could proceed stereoselectively with retention of configuration $^{70}$, a chiral $\mathrm{H}-\mathrm{P}(\mathrm{O})$ compound derived from $(4 \mathrm{R}, 5 \mathrm{R})$ Taddol derivative was used to achieve an enantioselective photocatalytic method with $\mathrm{CO}_{2}$ (Fig. 7c). Although the current protocol provides poor diasteroselectivity ratio, the diastereoisomers could be completely separated by column chromatography with good yields, which provides an alternative method for obtaining phosphonic acids-containing chiral $\alpha$-amino acids upon hydrolysis (For more information regarding other types of chiral H-P $(\mathrm{O})$ compounds, see Supplementary Figs. 2 and 3). The success of these experiments indicates the great potential application of the method in designing and synthesis of peptide drugs and ligands.

Preliminary investigation of reaction mechanism. To gain more insight to the reaction mechanism, several control experiments were conducted. As illustrated in Fig. 8a, the reaction was suppressed when the radical scavenger 2,2,6,6-tetramethyl-piperidinyloxyl (TEMPO) was employed. Moreover, the radical clock 
a Trapping with TEMPO

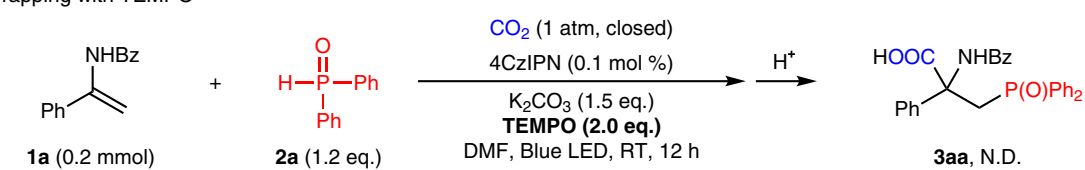

b Radical clock test

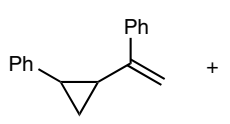

$16(0.2 \mathrm{mmol})$

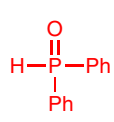

2a (1.2 eq.)

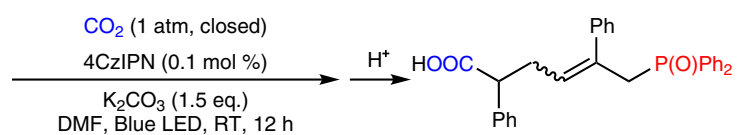

$17,62 \%, \mathrm{Z} / \mathrm{E}=2: 1$

C Isotope labelling with $D_{2} \mathrm{O}$<smiles>C=C([18O])c1ccccc1</smiles>

1a $(0.2 \mathrm{mmol})$

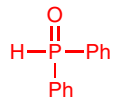

2a (1.2 eq.)

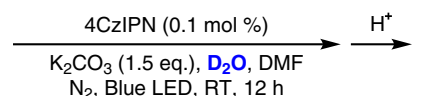

$\mathrm{N}_{2}$, Blue LED, RT, $12 \mathrm{~h}$

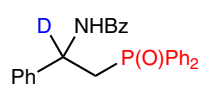

3 eq. $\mathrm{D}_{2} \mathrm{O}, 6 \mathrm{a}^{\prime}, 63 \%$ (32\%-D) 10 eq. $\mathrm{D}_{2} \mathrm{O}, 6 \mathrm{a}^{\prime}, 66 \%(69 \%-\mathrm{D})$

Fig. 8 Preliminary mechanistic studies. a The reaction was totally suppressed when the radical scavenger 2,2,6,6-tetramethyl-piperidinyloxyl (TEMPO) was employed. $\mathbf{b}$ Ring-opening occurred when cyclopropane substituted styrene was used as the substrate. $\mathbf{c}$ When different amounts of deuterated water was added, different degrees of deuterated products were obtained

test (Fig. 8b) also suggested that this transformation might rely on a radical process. Additionally, isotope-labeling studies provided a strong support for $\alpha$-amino benzylic anionic species acted as key intermediates (Fig. 8c). Besides, Stern-Volmer luminescence studies demonstrated that the excited state of $4 \mathrm{CzIPN}$ was quenched by $\mathbf{2} \mathbf{a}$ in the presence of base (see Supplementary Page 36) instead of 1a. These results indicate the involvement of a reductive quenching photocatalytic cycle in the reaction.

\section{Discussion}

In summary, we have described a general and practical strategy to realize the phosphonocarboxylation of alkenes with $\mathrm{CO}_{2}$ via visible-light photoredox catalysis. This method is suitable for diverse alkenes (enamides, styrenes, enolsilanes, and acrylates) and $\mathrm{H}-\mathrm{P}(\mathrm{O})$ compounds (diaryl- and dialkyl- phosphine oxides and phosphites), all of which undergo such reactions efficiently to access important and potentially bioactive $\beta$-phosphono carboxylic acids, including $\beta$-phosphono $\alpha$-amino acids. Notably, these redox-neutral and transition-metal-free reactions feature low catalyst loading, mild reaction conditions, high regio- and chemo-selectivities, good functional group tolerance, facile scalability, and easy product derivatization. Further application of this strategy is underway in our laboratory.

\section{Methods}

General procedure. An oven-dried Schlenk tube $(10 \mathrm{~mL})$ containing a stirring bar was charged with the substrates $(0.2 \mathrm{mmol})$. The Schlenk tube was then introduced in a glovebox, where it was charged with $\mathrm{H}-\mathrm{P}(\mathrm{O})$ compound $(49 \mathrm{mg}, 0.24 \mathrm{mmol}$, 1.2 eq.) and $\mathrm{K}_{2} \mathrm{CO}_{3}$ (41 mg, $0.3 \mathrm{mmol}, 1.5$ eq.). The tube was taken out of the glovebox and connected to a vacuum line where it was evacuated and back-filled with $\mathrm{CO}_{2}$ for 3 times. Then DMF $(2 \mathrm{~mL})$ and $4 \mathrm{CzIPN}(32 \mu \mathrm{L}, 0.1 \mathrm{~mol} \%, 5 \mathrm{mg}$ dissolved in $1 \mathrm{~mL}$ DMF) were added under $\mathrm{CO}_{2}$ flow. Finally, the reaction mixture in sealed tube was placed at a distance of $2-3 \mathrm{~cm}$ from a $30 \mathrm{~W}$ blue LED and stirred at room temperature $\left(25^{\circ} \mathrm{C}\right)$ for $12 \mathrm{~h}$. Then, the mixture was quenched with $4.5 \mathrm{~mL}$ of $\mathrm{H}_{2} \mathrm{O}$ and $0.5 \mathrm{~mL}$ of $2 \mathrm{~N} \mathrm{HCl}$ (aq.), extracted with ethyl acetate (EA) for at least 5 times, then concentrated in vacuo. The residue was purified by silica gel flash chromatography $\left(0.2 \% \mathrm{AcOH}\right.$ in $\left.\mathrm{CH}_{2} \mathrm{Cl}_{2} / \mathrm{MeOH} 100 / 1 \sim 20 / 1\right)$ to give the pure desired product. Note: (1) for styrenes ( $0.5 \mathrm{~mol} \% 4 \mathrm{CzIPN}$ and $\mathrm{Cs}_{2} \mathrm{CO}_{3}$ was used), flashed with petroleum ether/AcOEt $1 / 1$ to $0.67 \% \mathrm{AcOH}$ in petroleum ether/AcOEt $1 / 1$; (2) For acrylates ( 2 mol\% $4 \mathrm{CzIPN}$ and $\mathrm{Cs}_{2} \mathrm{CO}_{3}$ was used), flashed with petroleum ether/AcOEt $1 / 1$ to $0.67 \% \mathrm{AcOH}$ in petroleum ether/AcOEt $1 / 1$; (3) for phosphites ( $2 \mathrm{~mol} \% 4 \mathrm{CzIPN}$ and $\mathrm{Cs}_{2} \mathrm{CO}_{3}$ was used), before the addition of $0.5 \mathrm{~mL}$ $2 \mathrm{~N} \mathrm{HCl}$ (aq.), the quenched reaction mixture was extract three times for removing the inpurity, then $0.5 \mathrm{~mL}$ of $2 \mathrm{~N} \mathrm{HCl}$ (aq.) was added, the reaction mixture was extracted for 4 times, then the combined organic phase was concentrated in vacuum to obtain the pure product without chromatography.

\section{Data availability}

The authors declare that the data supporting the findings of this study are available within the article and its Supplemental Information files. Extra data are available from the author upon request. The crystallography data have been deposited at the Cambridge Crystallographic Data Center (CCDC) under accession number CCDC: 1885892 (methyl ester of 3aa) and can be obtained free of charge from www.ccdc.cam.ac.uk/getstructures.

Received: 27 February 2019 Accepted: 10 July 2019

Published online: 09 August 2019

\section{References}

1. Yin, G., Mu, X. \& Liu, G. Palladium(II)-catalyzed oxidative difunctionalization of alkenes: bond forming at a high-valent palladium center. Acc. Chem. Res. 49, 2413-2423 (2016).

2. Merino, E. \& Nevado, C. Addition of $\mathrm{CF}_{3}$ across unsaturated moieties: a powerful functionalization tool. Chem. Soc. Rev. 43, 6598-6608 (2014).

3. Koike, T. \& Akita, M. A versatile strategy for difunctionalization of carbon-carbon multiple bonds by photoredox catalysis. Org. Chem. Front. 3, 1345-1349 (2016)

4. Lan, X.-W., Wang, N.-X. \& Xing, Y. Recent advances in radical difunctionalization of simple alkenes. Eur. J. Org. Chem. 2017, 5821-5851 (2017).

5. Leca, D., Fensterbank, L., Lacôte, E. \& Malacria, M. Recent advances in the use of phosphorus-centered radicals in organic chemistry. Chem. Soc. Rev. 34, 858-865 (2005)

6. Wei, W. \& Ji, J.-X. Catalytic and direct oxyphosphorylation of alkenes with dioxygen and $\mathrm{H}$-phosphonates leading to $\beta$-ketophosphonates. Angew. Chem. Int. Ed. 50, 9097-9099 (2011).

7. Cai, B.-G., Xuan, J. \& Xiao, W.-J. Visible light-mediated C-P bond formation reactions. Sci. Bull. 64, 337-350 (2019).

8. Li, C.-X., Tu, D.-S., Yao, R., Yan, H. \& Lu, C.-S. Visible-light-induced cascade reaction of isocyanides and $\mathrm{N}$-arylacrylamides with diphenylphosphine oxide via radical C-P and C-C bond formation. Org. Lett. 18, 4928-4931 (2016).

9. Wang, N. et al. Catalytic diverse radical-mediated 1,2-cyanofunctionalization of unactivated alkenes via synergistic remote cyano migration and protected strategies. Org. Lett. 18, 6026-6029 (2016).

10. Xu, J., Yu, X. \& Song, Q. Silver-catalyzed radical-involved cascade cyclization of diphenylphosphine with cinnamamides: access to 2-phosphinoyl-3Hpyrrolo[1,2-a]indoles. Org. Lett. 19, 980-983 (2017).

11. Buquoi, J. Q., Lear, J. M., Gu, X. \& Nagib, D. A. Heteroarene phosphinylalkylation via a catalytic, polarity-reversing radical cascade. ACS Catal. 9, 5330-5335 (2019).

12. Murphy, P. Organophosphorus Reagents. (Oxford Univ. Press, Oxford, 2004). .

13. Peruzzini, M. \& Gonsalvi, L. (ed) Phosphorus Compounds: Advanced Tools In Catalysis And Material Sciences (Springer, Berlin, 2011).

14. Duffy, M. P., Delaunay, W., Bouit, P. A. \& Hissler, M. $\pi$-Conjugated phospholes and their incorporation into devices: components with a great deal of potential. Chem. Soc. Rev. 45, 5296-5310 (2016). 
15. Börner, A. (ed) Phosphorus Ligands In Asymmetric Catalysis: Synthesis And Applications (Wiley-VCH, Weinheim, 2008).

16. Kukhar, V. P. \& Hudson, H. R. (eds) Aminophosphonic and Aminophosphinic Acids, Chemistry And Biological Activity (John Wiley \& Sons, Ltd., Chichester, U.K., 2000).

17. Demmer, C. S., Krogsgaard-Larsen, N. \& Bunch, L. Review on modern advances of chemical methods for the introduction of a phosphonic acid group. Chem. Rev. 111, 7981-8006 (2011).

18. Gao, Y., Tang, G. \& Zhao, Y. Recent progress toward organophosphorus compounds based on phosphorus-centered radical difunctionalizations. Phosphorus Sulfur. Silicon Relat. Elem. 192, 589-596 (2017).

19. Li, J.-A. et al. Phosphinoyl radical-initiated $\alpha, \beta$-aminophosphinoylation of alkenes. Org. Lett. 19, 4704-4706 (2017).

20. Zhang, P.-Z. et al. Phosphinoyl radical initiated vicinal cyanophosphinoylation of alkenes. Org. Lett. 19, 5537-5540 (2017).

21. Yang, B. et al. Cerium(IV)-promoted phosphinoylation-nitratation of alkenes. Adv. Synth. Catal. 360, 4470-4474 (2018).

22. Zhang, C. et al. Silver-catalyzed radical phosphonofluorination of unactivated alkenes. J. Am. Chem. Soc. 135, 14082-14085 (2013).

23. Horsman, G. P. \& Zechel, D. L. Phosphonate biochemistry. Chem. Rev. 117, 5704-5783 (2017).

24. Lu, S.-Y. \& Hamerton, I. Recent developments in the chemistry of halogenfree flame retardant polymers. Prog. Polym. Sci. 27, 1661-1712 (2002).

25. Ntatsopoulos, V., Vassiliou, S., Macegoniuk, K., Berlicki, Ł. \& Mucha, A. Novel organophosphorus scaffolds of urease inhibitors obtained by substitution of Morita-Baylis-Hillman adducts with phosphorus nucleophiles. Eur. J. Med. Chem. 133, 107-120 (2017).

26. Graham, K. et al. Radiofluorinated derivatives of 2-(phosphonomethyl) pentanedioic acid as inhibitors of prostate specific membrane antigen (PSMA) for the imaging of prostate cancer. J. Med. Chem. 55, 9510-9520 (2012).

27. Majer, P. et al. Structural optimization of thiol-based inhibitors of glutamate carboxypeptidase II by modification of the $\mathrm{p} 1$ ' side chain. J. Med. Chem. 49, 2876-2885 (2006).

28. Jackson, P. F. et al. Design, synthesis, and biological activity of a potent inhibitor of the neuropeptidase $\mathrm{N}$-acetylated a-linked acidic dipeptidase. J. Med. Chem. 39, 619-622 (1996).

29. Blaskovich, M. A. T. Unusual amino acids in medicinal chemistry. J. Med. Chem. 59, 10807-10836 (2016)

30. Thomas, C. M. \& Ward, T. R. Artificial metalloenzymes: proteins as hosts for enantioselective catalysis. Chem. Soc. Rev. 34, 337-346 (2005).

31. Cowen, B. J. \& Miller, S. J. Enantioselective [3+2]-cycloadditions catalyzed by a protected, multifunctional phosphine-containing a-amino acid. J. Am. Chem. Soc. 129, 10988-10989 (2007).

32. Aresta, M. Carbon dioxide as chemical feedstock. (Wiley-VCH, Weinheim, 2010).

33. Tsuji, Y. \& Fujihara, T. Carbon dioxide as a carbon source in organic transformation: carbon-carbon bond forming reactions by transition-metal catalysts. Chem. Commun. 48, 9956-9964 (2012).

34. Liu, Q., Wu, L., Jackstell, R. \& Beller, M. Using carbon dioxide as a building block in organic synthesis. Nat. Commun. 6, 5933 (2015).

35. Kleij, A. W., North, M. \& Urakawa, A. $\mathrm{CO}_{2}$ catalysis. ChemSusChem 10, 1036-1038 (2017).

36. Luo, J. \& Larrosa, I. C-H carboxylation of aromatic compounds through $\mathrm{CO}_{2}$ fixation. ChemSusChem 10, 3317-3332 (2017).

37. Song, Q.-W., Zhou, Z.-H. \& He, L.-N. Efficient, selective and sustainable catalysis of carbon dioxide. Green Chem. 19, 3707-3728 (2017).

38. Tortajada, A., Juliá-Hernández, F., Börjesson, M., Moragas, T. \& Martin, R. Transition-metal-catalyzed carboxylation reactions with carbon dioxide. Angew. Chem. Int. Ed. 57, 15948-15982 (2018).

39. Maag, H. Prodrugs of carboxylic acids (Springer, New York, 2007).

40. Yan, S.-S. et al. Transition metal-catalyzed carboxylation of unsaturated substrates with $\mathrm{CO}_{2}$. Coord. Chem. Rev. 374, 439-463 (2018).

41. Zhang, L., Cheng, J., Carry, B. \& Hou, Z. Catalytic boracarboxylation of alkynes with diborane and carbon dioxide by an $\mathrm{N}$-heterocyclic carbene copper catalyst. J. Am. Chem. Soc. 134, 14314-14317 (2012).

42. Nogi, K., Fujihara, T., Terao, J. \& Tsuji, Y. Carboxyzincation employing carbon dioxide and zinc powder: cobalt-catalyzed multicomponent coupling reactions with alkynes. J. Am. Chem. Soc. 138, 5547-5550 (2016)

43. Gaydou, M., Moragas, T., Juliá-Hernández, F. \& Martin, R. Site-selective catalytic carboxylation of unsaturated hydrocarbons with $\mathrm{CO}_{2}$ and water. $J$. Am. Chem. Soc. 139, 12161-12164 (2017).

44. Hou, J. et al. Visible-light-driven alkyne hydro-/carbocarboxylation using $\mathrm{CO}_{2}$ via iridium/cobalt dual catalysis for divergent heterocycle synthesis. J. Am. Chem. Soc. 140, 5257-5263 (2018).

45. Butcher, T. W. et al. Regioselective copper-catalyzed boracarboxylation of vinyl arenes. Org. Lett. 18, 6428-6431 (2016).

46. Saito, N. et al. Enantioselective synthesis of $\beta$-amino acid derivatives via nickel-promoted regioselective carboxylation of ynamides and rhodium- catalyzed asymmetric hydrogenation. Org. Biomol. Chem. 14, 10080-10089 (2016).

47. Doi, R., Abdullah, I., Taniguchi, T., Saito, N. \& Sato, Y. Nickel-catalyzed hydrocarboxylation of ynamides with $\mathrm{CO}_{2}$ and $\mathrm{H}_{2} \mathrm{O}$ : observation of unexpected regioselectivity. Chem. Commun. 53, 7720-7723 (2017).

48. Takimoto, M., Gholap, S. S. \& Hou, Z. Cu-catalyzed alkylative carboxylation of ynamides with dialkylzinc reagents and carbon dioxide. Chem. Eur. J. 21, 15218-15223 (2015).

49. Saito, N., Sun, Z. \& Sato, Y. Nickel-promoted highly regioselective carboxylation of aryl ynol ether and its application to the synthesis of chiral $\beta$ aryloxypropionic acid derivatives. Chem. Asian J. 10, 1170-1176 (2015).

50. Prier, C. K., Rankic, D. A. \& MacMillan, D. W. C. Visible light photoredox catalysis with transition metal complexes: applications in organic synthesis. Chem. Rev. 113, 5322-5363 (2013).

51. Meggers, E. Asymmetric catalysis activated by visible light. Chem. Commun. 51, 3290-3301 (2015).

52. Koike, T. \& Akita, M. Fine design of photoredox systems for catalytic fluoromethylation of carbon-carbon multiple bonds. Acc. Chem. Res. 49, 1937-1945 (2016)

53. Xie, J., Jin, H. \& Hashmi, A. S. K. The recent achievements of redox-neutral radical C-C cross-coupling enabled by visible-light. Chem. Soc. Rev. 46, 5193-5203 (2017).

54. Marzo, L., Pagire, S. K., Reiser, O. \& König, B. Visible-light photocatalysis: does it make a difference in organic synthesis? Angew. Chem. Int. Ed. 57, 10034-10072 (2018)

55. Tan, F. \& Yin, G. Homogeneous light-driven catalytic direct carboxylation with $\mathrm{CO}_{2}$. Chin. J. Chem. 36, 545-554 (2018).

56. Yeung, C. Photoredox catalysis as a strategy for $\mathrm{CO}_{2}$ incorporation: direct access to carboxylic acids from a renewable feedstock. Angew. Chem. Int. Ed. 58, 2-13 (2018).

57. Yatham, V. R., Shen, Y. \& Martin, R. Catalytic intermolecular dicarbofunctionalization of styrenes with $\mathrm{CO}_{2}$ and radical precursors. Angew. Chem. Int. Ed. 56, 10915-10919 (2017).

58. Hou, J. et al. Visible-light-mediated metal-free difunctionalization of alkenes with $\mathrm{CO}_{2}$ and silanes or $\mathrm{C}(\mathrm{sp} 3)-\mathrm{H}$ alkanes. Angew. Chem. Int. Ed. 57, 17220-17224 (2018)

59. Ye, J-H. et al. Visible-light-driven iron-promoted thiocarboxylation of styrenes and acrylates with $\mathrm{CO}_{2}$. Angew. Chem. Int. Ed. 56, 15416-15420 (2017).

60. Seo, H., Katcher, M. H. \& Jamison, T. F. Photoredox activation of carbon dioxide for amino acid synthesis in continuous flow. Nat. Chem. 9, 453-456 (2016).

61. Fan, X., Gong, X., Ma, M., Wang, R. \& Walsh, P. J. Visible light-promoted $\mathrm{CO}_{2}$ fixation with imines to synthesize diaryl $\alpha$-amino acids. Nat. Commun. $\mathbf{9}$, 4936 (2018).

62. Ju, T. et al. Selective and catalytic hydrocarboxylation of enamides and imines with $\mathrm{CO}_{2}$ to generate $\alpha$, $\alpha$-disubstituted $\alpha$-amino acids. Angew. Chem. Int. Ed. 57, 13897-13901 (2018).

63. Mita, T., Higuchi, Y. \& Sato, Y. Carboxylation with $\mathrm{CO}_{2}$ via brook rearrangement: preparation of $\alpha$-hydroxy acid derivatives. Org. Lett. 16, 14-17 (2014).

64. Zhang, Z. et al. Lactonization of $\mathrm{C}\left(\mathrm{sp}^{2}\right)$ - $\mathrm{H}$ bonds in enamides with $\mathrm{CO}_{2}$. Chin. J. Chem. 36, 430-436 (2018).

65. Semenzin, D., Etemad-Moghadam, G., Albouy, D., Diallo, O. \& Koenig, M. Dual radical/polar pudovik reaction: application field of new activation methods. J. Org. Chem. 62, 2414-2422 (1997).

66. Yoo, W.-J. \& Kobayashi, S. Hydrophosphinylation of unactivated alkenes with secondary phosphine oxides under visible-light photocatalysis. Green Chem. 15, 1844-1848 (2013)

67. Ma, J.-A. Catalytic asymmetric synthesis of $\alpha$ - and $\beta$-amino phosphonic acid derivatives. Chem. Soc. Rev. 35, 630-636 (2006)

68. Enders, D., Saint-Dizier, A., Lannou, M.-I. \& Lenzen, A. The phospha-michael addition in organic synthesis. Eur. J. Org. Chem. 2006, 29-49 (2006).

69. Xu, Z.-H. et al. Group I mGluR antagonist rescues the deficit of D1-induced LTP in a mouse model of fragile X syndrome. Mol. Neurodegener. 7, 24 (2012).

70. Jessop, C. M., Parsons, A. F., Routledge, A. \& Irvine, D. J. Radical addition reactions of chiral phosphorus hydrides. Tetrahedron Asymmetry 14, 2849-2851 (2003).

\section{Acknowledgements}

We thank Prof. Jason J. Chruma (Sichuan University) for valuable help. Financial support was provided by the National Natural Science Foundation of China (21822108 and 21772129), the Fok Ying Tung Education Foundation (161013), the "973" Project from the MOST of China (2015CB856600), the "1000-Youth Talents Program", and the Fundamental Research Funds for the Central Universities. We also thank the comprehensive training platform of the Specialized Laboratory in the College of Chemistry at Sichuan University for compound testing. 


\section{Author contributions}

D.G.Y. and Q.F. conceived and designed the study, and wrote the paper. Q.F., Z.Y.B. J.H.Y., T.J., H.H., and L.L.L. performed the experiments and mechanistic studies. Q.F. performed the crystallographic studies. All authors contributed to the analysis and interpretation of the data.

\section{Additional information}

Supplementary Information accompanies this paper at https://doi.org/10.1038/s41467019-11528-8

Competing interests: A Chinese Patent on this work has been applied with the number (201910599890.5) on 4 July 2019. The remaining authors declare no competing interests.

Reprints and permission information is available online at http://npg.nature.com/ reprintsandpermissions/

Peer review information: Nature Communications thanks anonymous reviewer(s) for their contribution to the peer review of this work.
Publisher's note: Springer Nature remains neutral with regard to jurisdictional claims in published maps and institutional affiliations.

(c) (i) Open Access This article is licensed under a Creative Commons Attribution 4.0 International License, which permits use, sharing, adaptation, distribution and reproduction in any medium or format, as long as you give appropriate credit to the original author(s) and the source, provide a link to the Creative Commons license, and indicate if changes were made. The images or other third party material in this article are included in the article's Creative Commons license, unless indicated otherwise in a credit line to the material. If material is not included in the article's Creative Commons license and your intended use is not permitted by statutory regulation or exceeds the permitted use, you will need to obtain permission directly from the copyright holder. To view a copy of this license, visit http://creativecommons.org/ licenses/by/4.0/.

(C) The Author(s) 2019 